\title{
41919:-
}

\section{O protagonismo do banal e a performance nas bandas desenhadas documentais}

\author{
Felipe Muanis
}

\section{Resumo:}

Este trabalho visa analisar estratégias da banda desenhada norte-americana dos anos 1960, em especial produzida por Robert Crumb e Harvey Pekar e rever a sua influência nos quadrinhos documentais contemporâneos, nos quais a autorreferencialidade e a banalidade se evidenciam como caraterísticas da banda desenhada moderna. A proposta é dialogar com a teoria da performance de Paula Sibilia, com a presença do homem comum nas mídias e, por fim, com os conceitos de "virada demótica" de Graeme Turner e de "democratainment" de John Hartley.

Palavras-chave: BD documental; banal; homem comum; performance; autorreferência.

\section{Abstract:}

The aim of this paper is to analyse the north-american comics strategies from the 60's, especially that ones produced by Robert Crumb and Harvey Pekar and to rethink their influence in contemporary documentary comics, in which the self-reference and the banality become evident properties of the modern comics. The proposition here is to open the dialogue with the theory of performance, from Paula Sibilia, the presence of the ordinary men in the media and, ultimately, Graeme Turner's "demotic turn" and John Hartley's "democratainment" concepts.

Keywords: Documentary comics; banal; ordinary man; performance; self-reference. 
Poucos homens são dotados da capacidade de ver; há ainda menos homens que possuem a capacidade de se exprimir. Charles Baudelaire, Sobre a Modernidade

Os personagens de $B D$ existem apenas para viverem intensamente. Fresnault-Deruelle, O espaço interpessoal nos comics Será que, nos quadrinhos, um personagem, para se realizar plenamente, precisaria ser um "herói", com todas as consequências ficcionais e mitológicas que tal fato acarreta? Moacy Cirne, Heróis e personagens - talvez sim, talvez ficção

\section{Introdução}

Nos últimos anos, tornou-se frequente a pesquisa em torno de um fenômeno na cultura das mídias: a ascensão do homem comum como protagonista de suas narrativas. Estas ocupam, prioritariamente, de acordo com diversos autores, o espaço das mídias audiovisuais, especialmente com o advento da tecnologia digital. Desse modo, televisão, cinema, internet e seus cruzamentos seriam os locais preferenciais dessa participação. Esse personagem popular, ou homem ordinário, para alguns, ganhou tamanho, espaço e importância nos produtos midiáticos contemporâneos e na academia, a ponto de se tornar o grande diferencial para concepções que muitas vezes se revelaram dogmáticas com o tempo, por parte de alguns teóricos, especialmente no que concerne a alguns estudos do cinema-documentário. Contudo, independentemente de juízos teóricos algumas vezes excludentes, é inegável e notável o reconhecimento desse fenômeno e de como a participação cada vez maior do homem comum tem transformado as mídias contemporâneas.

Nesse sentido, cabe uma atenção para as artes gráficas, onde desde muito cedo a representação do homem comum ganhava a atenção da população dos crescentes centros urbanos, através das páginas dos jornais. O cotidiano da Paris na segunda metade do século XIX era ilustrado por Constantin Guys, que Charles Baudelaire enalteceu e considerou como o símbolo da vida moderna no livro Sobre a Modernidade, editado em 1863: um "homem do mundo, isto é, homem do mundo inteiro, homem que compreende o mundo e as razões misteriosas e legítimas de todos os seus costumes." (Baudelaire, 1996: 14). De acordo com o poeta francês, para Guys, a beleza valorizada não era aquela dos museus, mas a beleza encontrada na vida diária e cotidiana. Era a figura do flâneur, para quem a multidão nas ruas é o seu universo, do pintor de hábitos e costumes, do observador que não tematizava mais as coisas eternas e os grandes temas, fossem estes heroicos ou religiosos. Tratava-se, sim, de um pintor das circunstâncias, do que essa banalidade sugere como eterno. 
Na mesma época da publicação do livro de Baudelaire, mais precisamente um ano depois, em 1864, o italiano Angelo Agostini começava a sua carreira de cartunista no Brasil, publicando o jornal ilustrado Diabo Coxo em São Paulo, que teve duração curta. Mudou-se para o Rio de Janeiro e em 1869 estreava As aventuras de Nhô-Quim nas páginas da revista $A$ Vida Fluminense, considerada por muitos como a primeira banda desenhada do mundo ${ }^{1}$. Posteriormente, em 1876, Agostini cria outro personagem de banda desenhada, dessa vez para a Revista llustrada, o Zé Caipora. Ambas as bandas desenhadas retratavam o cotidiano dos seus protagonistas, na época do Brasil Império, mostrando escravos, comerciantes, burguesia e nobreza, utilizando humor e críticas de costumes.

Em comum entre Guys e Agostini, está a tentativa de representar a vida cotidiana através de personagens comuns. Na contemporaneidade, inúmeros autores tratam as representações centradas na ideia do cotidiano e do homem comum, reforçando o potencial desses acontecimentos banais. Mas as discussões teóricas neles alicerçadas pouco se alongam normalmente no que diz respeito à banda desenhada, mídia em que Angelo Agostini foi, sem dúvida, um dos mais importantes precursores, podendo contribuir muito para estas investigações.

Nesse sentido, dando uma guinada no tempo e no espaço, este trabalho visa rever estratégias da banda desenhada estadunidense nos anos 1960, e repensar a sua influência nos quadrinhos documentais contemporâneos ${ }^{2}$, para, assim, dialogar com teorias que tratam das propostas de performance de Paula Sibilia, do homem comum das mídias e dos conceitos de Graeme Turner, expressos nomeadamente na sua crítica à ideia de "democratainment" de John Hartley.

Turner (2010) problematiza a participação popular nas mídias fazendo uma distinção entre o "democrático" e o "demótico", ou seja, a mídia participa da produção da cultura, mas isto não redunda necessariamente em uma participação efetivamente democrática. Sibilia (2015), por sua vez, aponta que algumas dessas narrativas, especialmente as autorreferentes, parecem ter deslocado a ênfase do narrador para o protagonista, o que condiz com o objeto de pesquisa aqui proposto. Trata-se, portanto, da manifestação e da ascensão do banal, ou seja, do comum, do trivial e do vulgar, para uma posição de protagonismo em narrativas midiáticas nos últimos 50 anos.

\footnotetext{
${ }^{1}$ Normalmente considera-se, erroneamente, como a primeira banda desenhada do mundo, a tira de jornal Yellow Kid, criada por Richard Outcault, publicada entre 1894 e 1898 nos Estados Unidos, primeiro na revista Truth e depois no jornal New York World. Na verdade, a banda desenhada se chamava Hogan's Alley e o seu personagem principal, Mickey Dugan, ficou conhecido como Yellow Kid por sempre vestir uma mesma túnica amarela em que apareciam as frases de seus diálogos.

2 Para mais detalhes, ver os artigos "O quadrinho documental e a tradução da cidade" e "Dokumentarische Comics als Übersetzung des Altäglichen" de Felipe Muanis (Muanis, 2013 e 2014).
} 
Nesse caso, serão importantes as análises de dois eixos complementares para a apreciação das bandas desenhadas: uma produção autorreferente, que começa com Robert Crumb e Harvey Pekar nas décadas de 1960-1970, e a ascensão do underground e da contracultura até à BD documental contemporânea, resultando em trabalhos como os de Marjane Satrapi e de Joe Sacco. Entende-se aqui como banda desenhada documental um gênero literário específico, que agrega diversos subgêneros, como os discursos jornalísticos, autobiográficos, os relatos de viagem $\mathrm{e}$ as reconstituições históricas, muito influenciados por estratégias provenientes de outras mídias.

Busca-se aqui, com esta proposta, contemplar dois objetivos: inserir a banda desenhada nas discussões teóricas sobre o homem comum e o banal na cultura das mídias e, por fim, refletir sobre o quanto a mudança de lugar do personagem popular para o interior das mídias (ao contrário da sua anterior limitação ao exterior, como espectador), é ou não apenas um fenômeno da atualidade. Para tanto, é necessária a análise com um relato detalhado do surgimento do banal nas bandas desenhadas.

\section{A transgressão da juventude e os comix}

A vida ordinária é um material demasiadamente complexo ${ }^{3}$ Harvey Pekar

Em uma passagem de seu livro Apocalípticos e integrados (2001), Umberto Eco faz uma análise dos quadrinhos de Steve Canyon, criado por Milton Caniff, e ressalta a constituição física do personagem, que remete à figura do galã e ao star-system do cinema clássico de Hollywood. De fato, boa parte das bandas desenhadas estadunidenses não voltadas para o humor ou para o público infantil seguiam esses parâmetros estéticos. É nos anos 1960, contudo, que, se não há uma ruptura nesse modelo, pode afirmar-se que tem início uma vertente oposta, na qual personagens que não seguem o mesmo padrão de beleza e que são mundanos e vulgares ganham as páginas das bandas desenhadas, levando essa mídia e forma de expressão para o que se poderia chamar de uma BD moderna. Quebram-se tabus, afronta-se a sociedade e a narrativa das bandas desenhadas se transforma, tornando-se mais autorreferencial e metalinguística; a quebra da quarta parede para o leitor, no sentido brechtiano, torna-se uma constante. É o tempo das BD's underground, dos fanzines e dos comix. É a banda desenhada da contracultura, que, na forma, se torna menos literária e menos narrativa, com rupturas nas relações de espaço-tempo.

\footnotetext{
${ }^{3}$ Citado por Schikowski (2009: 99); tradução do autor.
} 
A também chamada nona arte começa a caminhar na direção do underground com as revistas da EC Comics, ${ }^{4}$ especialmente ainda na década de 1950. Seus títulos Crypt of terror, Frontline Combat e Weird science fantasy representavam mudanças na forma de narrar a história. Em Crypt of terror, por exemplo, sempre havia um narrador sobrenatural, normalmente uma bruxa ou um zumbi, que abria e encerrava cada conto, geralmente curto, dirigindo-se e falando diretamente para o leitor, fitando-o. Além disso, os contos pareciam abandonar definitivamente o bom gosto das habituais bandas desenhadas do establishment. Virtuosismo da violência, erotização e relações humanas mundanas: tudo é contrário aos valores tradicionais da família dos Estados Unidos. A transgressão torna-se ainda mais contundente com o lançamento da revista $M A D$, de Harvey Kurtzman, na mesma editora. Esta apresentava, segundo Luis Vigil, um "humor agressivo, impetuoso e subversivo", (Vigil, 1971: 102), que tudo satirizava, ridicularizando o american way of life e seu star-system e parodiando os próprios quadrinhos clássicos da era de ouro, como Flesh Garden, Superduperman, Prince Violent e Bat Boy and Rubin. De acordo com Vigil, as crianças passam a deixar de ser atraídas pelos valores da geração de seus pais:

O cenário já estava definido: as mudanças sociais na juventude norte-americana, com sua nova atitude de protesto, de rebelião, de rechaço total dos valores de seus pais, haviam proporcionado o mercado adequado para um novo tipo de banda desenhada, que não podia ser satisfeito pelos produtos oferecidos pela indústria cultural. (Vigil, 1971: 102)

É nessa condição que se estabelece o avanço da BD underground nos Estados Unidos na década de 1960, também conhecido como comix, em oposição à banda desenhada overground, ou seja, clássica, mais comercial, editada pelas grandes editoras. As primeiras experiências vieram com The adventures of Jesus, em 1962, de Foolbert Sturgeon (pseudônimo de Frank Stack), e God nose, em 1964, de Jack Jaxon, esta impressa em máquinas Xerox. Na verdade, esses e outros desenhistas deste tipo de banda desenhada, como Manuel Rodriguez (conhecido como Spain ou Spain Rodriguez) e S. Clay Wilson, vieram da cultura do fanzine ${ }^{6}$, que era caraterizada por publicações caseiras e com uma temática específica, sem periodicidade, feitas e editadas pelos próprios artistas (que muitas vezes eram amadores e nem sabiam desenhar), por meio de mimeógrafos ou fotocopiadoras, destinadas a um público pequeno e sem pretensões de lucro. Foi o veículo fundamental para o lançamento dos novos artistas da banda desenhada da contracultura na década de 1960 e é essencial

\footnotetext{
${ }^{4}$ A Entertaining Comics funcionou nas décadas de 1940 e 1950, sendo finalmente vendida em 1960, depois de muita perseguição da sociedade conservadora estadunidense.

${ }^{5}$ Tradução do autor.

${ }^{6}$ A palavra fanzine vem da aglutinação da expressão em inglês fan magazine.
} 
para a ascensão do banal na BD. O texto de Luís Vigil, editor de fanzines e banda desenhada underground em Espanha, retrata o seu leitor, no contexto da época: uma juventude descontente, de hippies que consomem maconha, para a qual os policiais, os militares no Vietnã e a Igreja se tornam os vilões. Para o autor, os comix não são uma transformação ou evolução da banda desenhada, mas um "recomeço do zero" (Vigil, 1971: 107), no qual se reestabelecem novos valores, distintos da sociedade da época. Contudo, é com Robert Crumb e sua revista All New Zap Comics, vendida por ele e sua esposa em 1968 na zona hippie de São Francisco, que explode o comix. O sucesso do comix com esse jovem foi imediato, e o triunfo de alguns de seus desenhistas - $\mathrm{e}$ especialmente de Crumb - incentivou outros pelo mesmo caminho. A produção das revistas ganhava contornos quase artesanais, sendo estas impressas em gráficas de pequeno porte. Com divisão de lucros entre seus artistas e as gráficas, e sem editores, garantia-se não apenas um retorno financeiro maior, como maior liberdade de expressão para o artista, resultando nas histórias mais subversivas possíveis para a moral da época. O mesmo acontecia com a distribuição, que era feita muitas vezes pelos próprios artistas, mas não nas lojas especializadas em banda desenhada. Crumb, por exemplo, distribuía suas publicações para venda em lojas de pornografia e headshops. ${ }^{7}$ De acordo com Álvaro de Moya (1986: 215), Crumb não desenhava por dinheiro, mas por prazer. Inclusive chegou a fazer trabalhos comerciais, como a conhecida capa do disco Cheap Thrills, de Janis Joplin, em 1968, para a qual, já famoso, nunca teria buscado seu pagamento.

Influenciado por William Burroughs, Jack Kerouak e J. D. Salinger, Robert Crumb criava personagens que eram pessoas comuns, ou retratava pessoas reais que nunca pareciam abstratas, como Harvey Pekar (este na revista American Splendor), ou se autorretratava em todas as suas neuroses, inconstâncias e taras.

Por meio de sua educação de cunho católico, ele se desenha livre de seus desejos. Suas histórias abriam a porta sobre a vulgaridade e a obscenidade. As bandas desenhadas descobriram a pornografia como uma alegoria muito normal. [...] A representação de sexualidade de Crumb foi sempre provocativa. Ele tinha seus próprios rituais e anseios, os quais apresentou e, portanto, pôs em discussão. Suas BDs foram celebradas pelo movimento, odiado pelos cidadãos. (Schikowski, 2009: $95)^{8}$

Desse modo, se a banda desenhada da contracultura já tematizava o trivial e o vulgar como maneira de subversão, Robert Crumb esgarça esses limites, elege-se como seu personagem e traz sua própria banalidade como motivação de suas narrativas, modificando a própria BD e inaugurando possivelmente a estratégia contemporânea de

\footnotetext{
${ }^{7}$ Headshops são lojas nos Estados Unidos destinadas à venda de produtos acessórios para consumidores de maconha.

8 Tradução do autor.
} 
relatos autobiográficos de homens comuns nas bandas desenhadas. Para Schikowski (2009), o trabalho de Crumb resultou no protótipo das BDs autobiográficas e inaugurou o que se pode classificar de banda desenhada moderna.

Em 1976, Crumb junta-se a Harvey Pekar, um almoxarife decadente em um hospital em Cleveland que também escrevia sobre música para um fanzine local. Pekar começa a escrever BDs realistas, retratando sua vida ordinária, entediada, e desenhando com bonecos palito. Estas ganham o interesse e a admiração de Crumb, que resolve ilustrar as suas histórias, que se tornam sucessos de venda. Suas narrativas em muito se assemelhavam ao estilo de Charles Bukowski, e, para Schikowski (2009), o sucesso de American Splendor, a revista de Pekar e Crumb, foi essencial para a banda desenhada autobiográfica ser aceita como gênero literário. Pekar se torna uma celebridade e passa a ser constantemente explorado de maneira jocosa pela mídia e por programas de televisão na década de 1980, como o Late Show de David Letterman, por sua personalidade atípica e antissocial, o que é bem retratado no filme Anti-herói americano (American Splendor, de Robert Pulcini e Shari Springer Berman, 2003). De acordo com Klaus Schikowski,

Pekar é um autor no sentido mais verdadeiro: seu estilo de narrar é divertido e despretensioso, adequado ao dia a dia retratado. Ele também reconhece o potencial das bandas desenhadas autobiográficas, experimenta em conformidade com diferentes maneiras de apresentar a narrativa. Oferece trechos de monólogos, partes de pura conversação, histórias em primeira pessoa, mas também histórias com um narrador autoral. Mas rejeita a ideia da autobiografia como um gênero literário: 'Autobiografias não são escritas para acomodar regras predefinidas'.' (Schikowski 2009: 99) ${ }^{9}$

Diante das estratégias autobiográficas de narrar os acontecimentos iniciadas por Robert Crumb, tomando como perspectiva o desenvolvimento das bandas desenhadas a partir de então, nas quais pessoas comuns tornam-se os grandes personagens dessas narrativas, e pensando ainda na multiplicação de relatos e gêneros, pode-se dizer, sem hesitação, que as experiências autorreferentes no comix, em especial os trabalhos de Robert Crumb e de Harvey Pekar, podem ser consideradas, junto ao cinema documentário, uma das importantes matrizes da BD documental, este último pensado como gênero. Desse modo, Crumb, além de recomeçar a banda desenhada do zero, como afirma Vigil, dá início ao quadrinho moderno e inaugura a BD documental.

Se o underground, a contracultura, os fanzines e os comix foram os responsáveis por uma geração de desenhistas que fundaram a BD autobiográfica nos Estados Unidos, é inegável que Robert Crumb foi seu grande artífice. Schikowski lembra, contudo, que Crumb se envolve cada vez mais em suas narrativas autobiográficas, consolidando-se

\footnotetext{
${ }^{9}$ Tradução do autor.
} 
como um personagem de banda desenhada que se dirige diretamente a seus leitores de uma maneira um tanto egocêntrica. Em 1971, em uma página da revista The Truth, representa-se como o "cartunista e herói popular R. Crumb" (Schikowski, 2009: 97) ${ }^{10}$. Nesse sentido, seu comportamento não deve ser condenado, mas percebido dentro de um processo mais amplo de performance.

Paula Sibilia (2015) aponta o papel da performance na contemporaneidade e lembra Richard Schechner, que afirmava que os comportamentos dos indivíduos são, em si, performances: a escolha das roupas, o posicionamento diante das pessoas e da família, no dia-a-dia. Enfim, pode concluir-se que viver é performar. Tretiakov, por outro lado, durante o construtivismo russo, também usava o clássico exemplo do lenhador, que, em sua atividade de trabalho, corta a lenha e se apresenta de uma maneira mas que, se tem consciência que está a ser filmado por uma câmera ou quiçá observado, perde seu componente de verdade justamente por performar para um olhar e por seu gesto se aproximar de uma encenação. De fato,

(o)s personagens só existem enquanto são observados: somente são alguém se outros veem sua performance. Essa é, precisamente, uma das definições possíveis para essa outra entidade escorregadia, o personagem: não se trata aqui de remarcar a ambígua - e cada vez menos relevante — diferenciação entre realidade e ficção, mas de encarnar uma subjetividade que somente existe se estiver sob observação. (Sibilia, 2008: 265)

O que Crumb e Pekar fazem em suas bandas desenhadas, ao se retratarem, é performar para os outros, deixando de ser apenas as personas dos autores e transformando-se em personagens. É justamente o que diferencia o relato autobiográfico para Paula Sibilia (2008: 30), com base na crítica literária de Philippe Lejeune, para quem o pacto de leitura entre autor e leitor, nesse tipo de obra, faz com que, para o leitor, autor, narrador e protagonista se fundam em uma só pessoa.

Para Aurelio Sahagun (1971: 246), o comix é uma banda desenhada de autor, no qual existem poucos personagens constantes, que variam em cada história, mas quando existem são de propriedade do próprio artista, em contraponto à banda desenhada de ator, na qual o personagem é repetido e atende a uma correspondência aos padrões tanto de serialidade quanto de beleza cultivados pela burguesia ocidental, consumido por meio do star-system cinematográfico. As BDs autobiográficas, portanto, apresentavam não o próprio autor e narrador como seu personagem constante, mas sua performance como o protagonista de suas histórias. Após a figura do autor ser colocada em xeque no campo teórico, a personificação do autor como protagonista na $\mathrm{BD}$ underground parece dar nova dimensão à discussão.

\footnotetext{
${ }^{10}$ Tradução do autor.
} 
$\mathrm{Na}$ época, portanto, os personagens das BDs underground e mesmo do overground norte-americanos tinham características que se aproximavam, como podiam, do homem comum. Nos anos 1960, vivia-se a chamada era de prata nos quadrinhos mainstream nos Estados Unidos, com Stan Lee criando personagens de superheróis mais humanos na Marvel, como o Homem Aranha: este foi uma proposta de trazer o super-herói para os problemas do cotidiano, ao tematizar suas dificuldades para pagar as contas e conciliar sua vida de combatente do crime com a de estudante. De outro lado, os personagens da contracultura tinham sua banalidade explorada nas BDs underground de forma mais contundente. Eram tudo, menos belos, sem família estruturada ou sem ser bem aceitos pela sociedade. Para eles, ter a luz cortada ao final do mês era o menor de seus problemas. De acordo com Steve Davidson, no prólogo da consagrada revista underground holandesa Gung ho! All American Comicks, de 1970, sobre os personagens das bandas desenhadas daquela época:

Nem todos resultam completamente familiares a qualquer um, mas estão suficientemente próximos de uma tipologia universal como para que muitos de nós possamos reconhecê-los. Não é necessário conhecer a banda desenhada tradicional americana dos últimos 30 anos para que estejamos confortáveis entre os atuais personagens da $\mathrm{BD}$ da contracultura, porque, definitivamente, tanto os personagens da banda desenhada establishment como do underground são extraídos da vida americana. Nesse sentido, pode-se dizer que a BD contracultural é um dos mais adequados retratos da vida americana que se podem encontrar nos meios de comunicação e nas artes contemporâneas. (Davidson, 1970: 2) ${ }^{11}$

É justamente o retrato da vida cotidiana que se desenvolve rapidamente nos quadrinhos das décadas seguintes até os dias de hoje, tanto nos Estados Unidos quanto em outras partes do mundo, em inúmeros subgêneros a partir do gênero de BD documental, sejam eles autobiográficos ou não. Desde os personagens cotidianos nas graphic novels de Will Eisner às longas produções de banda desenhada autobiográfica de Justin Green (Binky Brown meets the holy virgin Mary, 1972) e Art Spiegelman (Maus, 1980), e, a partir dos anos 1990, aos quadrinhos dos estadunidenses Daniel Clowes (Eightball, 1989), Adrian Tomine (Sleepwalk and other stories, 1998), Chester Brown (Playboy, 1992) e Craig Thompson (Retalhos, 2003), entre outros, até aos relatos autobiográficos. Referimo-nos às narrativas de viagem do alemão Reinhard Kleist (Havanna, 2008), do português Ricardo Cabral (Israel, 2009), do francês naturalizado japonês Frédéric Boilet (O espinafre de Yukiko, 2001); às reportagens em zonas de conflito do maltês Joe Sacco (Palestina, 1995), do francês Emmanuel Guibert (Le photographe, 2003-2006), de regimes políticos fechados como os do canadense Guy Delisle (Shenzhen, 2000) ou de grupos de extrema-direita fechados abordados pelos alemães David Schraven e Jan Feindt (Weisse Wolfe, 2015). A estas juntam-se as autobiografias da iraniana Marjane

\footnotetext{
11 Tradução do autor.
} 
Satrapi (Persepolis, 2000-2003), do japonês Ken Nakazawa (Hadashi no Gen, 19731985), do brasileiro André Diniz (Chalaça, o amigo do rei, 2005) e do franco-persa Riad Sattouf (L'Arabe du Futur, 2014). O que é comum entre todas é serem histórias de pessoas comuns ou performances autobiográficas de autores/narradores/personagens que vivem intensamente, mas que não precisam ser grandes heróis míticos, fantasiosos ou superpoderosos para que sejam dignos de protagonizar suas narrativas. Para Paula Sibilia:

Considerando as complexas mutações que vêm afetando a produção de subjetividades nas últimas décadas, uma certeza volta à tona: não é de se estranhar que a performance como gênero artístico tenha surgido nos anos 1960-70. Tampouco surpreende que isso tenha ocorrido no seio da tradição espetacular dos Estados Unidos, num momento de fortes questionamentos atrelados aos movimentos da contracultura; e que, meio século depois, esteja se expandindo pelo planeta globalizado do século XXI com outras tonalidades e com tanto vigor. (Sibilia, 2015: 358$)^{12}$

Tributárias originalmente dos comix e dos fanzines, as obras contemporâneas citadas anteriormente deixaram a produção artesanal na história, ainda que essa prática nunca tenha deixado de ocorrer entre seus jovens artistas. Tampouco continuaram sendo vendidas em lojas de pornografia. Hoje, tais bandas desenhadas recebem o aval de uma crítica especializada, bem como da própria sociedade, reconhecidos como literatura e detentores de importantes prêmios, sendo que muitas vezes tematizam ainda a violência e a erotização. Estão presentes em livrarias e são produzidos por editoras respeitáveis, com traduções e versões em outros países, muitas vezes em edições luxuosas, no seu cuidado gráfico e editorial. Um cenário bem diferente do encontrado por Crumb, Shelton, Pekar e Moscoso nos anos 1960. As bandas desenhadas nos Estados Unidos, na Europa e no Japão tornaram-se um sólido mercado e, apesar de serem, como toda atividade artística, feitas com paixão, deixaram de ser uma atividade de loucos idealistas sem maiores preocupações com o retorno financeiro.

E, nesse sentido, talvez a BD autobiográfica e a banda desenhada dos personagens banais, em suas particularidades, desde os primeiros momentos dos comix dos anos 1960 até às BDs documentais contemporâneas, possam contribuir para as discussões acerca da maior participação do homem comum na cultura das mídias, trazendo novas variáveis para o debate que se segue.

\section{Modernidade e intimidade nas mídias}

Os relatos de homens comuns são uma prática recorrente nas mais diversas mídias. De acordo com Vera Figueiredo (2014), o homem banal entra em cena no romance

\footnotetext{
12 Tradução do autor.
} 
moderno, desde Miguel de Cervantes. Originário do interesse da burguesia com a vida dos populares após a Revolução Francesa, as narrativas em que o fascínio pelos jovens da cidade, pelo baixo mundo que os cerca e pela vida cotidiana da classe média teve seu auge no século XIX com Eugène Sue e Balzac. Foi também quando Flaubert inaugurou o romance realista com Madame Bovary, uma mulher trivial.

Além do protagonismo dos anônimos, outra marca nas bandas desenhadas de Crumb e Pekar, conforme visto anteriormente, são as narrativas em primeira pessoa. Essas ganham proeminência no modernismo, que questionava a dicção realista e problematizava a enunciação. Nesse sentido, é preciso ainda distinguir dois sentidos de autorreferência. $\mathrm{O}$ primeiro é relativo à metalinguagem, à reflexividade, quando $\mathrm{O}$ texto dobra-se sobre si mesmo, criticamente, reflexivamente. O segundo é relativo à pessoa que faz referência a si mesma, a sua vida, o que não é necessariamente metalinguagem.

Ambas as estratégias, de construção de relatos de cotidiano através do protagonismo do homem ordinário e de discursos em primeira pessoa não são a mesma coisa mas podem acontecer juntas em complementaridade, como acontecia nas bandas desenhadas de Pekar e Crumb. No caso destes, como são os próprios autores, deixam de ser apenas personagens comuns em seus discursos por serem, eles próprios, seus autores.

O cinema encontrou o homem comum desde seu início, com os irmãos Lumiére e passando depois pelas diversas correntes de documentários e diversas cinematografias. Na fiç̧ão, este tipo de personagem se torna o protagonista de suas histórias especialmente no pós-guerra, com o neorrealismo italiano de De Sica, Rossellini ou mesmo com o pós-neo-realismo de Pasolini. De seguida, viria o aprofundamento das teorias e estratégias de cinedocumentário que se tornou reflexivo a partir do cinéma-vérité de Jean Rouch. O neorrealismo e o cinema-vérité teriam ambos influenciando os movimentos de cinema novo na década de 1960 por diversos países, inclusive na América Latina. A televisão, mais nova, em meados da década de 1980, de acordo com as teorias de "neotelevisão" de Umberto Eco, Francesco Casetti e Roger Odin, vai para o espaço do íntimo. Assim, as pessoas comuns passam a fazer parte de suas imagens. Não são mais apenas os especialistas e autoridades que ocupam a tela, mas o povo, que começa a participar de programas. É nesse momento que começam os talk-shows e reality shows, com a presença cada vez maior do homem comum, de pessoas ordinárias, que conquistam muito mais que os 15 minutos de fama propostos por Andy Warhol. A fotografia, aqui não trabalhada mas não menos importante, o cinema e a televisão, de fato, potencializaram a participação desse personagem banal desde seu surgimento. Para Vera Figueiredo, 
Com a consolidação das artes mecânicas, surgiria o que Jacques Rancière chamou de regime estético das artes, que levava à ruína o regime de representação tal como era constituído até então: "Um sistema em que a dignidade dos sujeitos comandava a dignidade dos gêneros de representação", que "reservava a tragédia para os nobres, a comédia para a plebe" (2005, p. 47). Daí em diante o anônimo tornava-se tema de arte, em detrimento das histórias dos grandes feitos e dos grandes personagens, instaurando-se um novo regime de verdade, a partir de uma nova racionalidade do banal e do obscuro que se contrapõe às ordenações aristotélicas (2005, p. 56). (Figueiredo, 2014: 12).

Além da profusão do anônimo, na contemporaneidade, a exibição generalizou-se tanto na televisão quanto na internet. Nesta última, os vídeos e fotos caseiras tematizam seus próprios usuários, alguns inclusive com imagens e sequências que exploram o íntimo, em aplicativos como Instagram, Snapchat e Periscope, entre tantos outros, ocupando as redes sociais com as suas versões de suas próprias narrativas, ou seja, performando sua história. Muitas dessas construções parecem não diferir tanto do que Crumb e Pekar faziam nas décadas de 1960 e 1970 mas há, de fato, uma diferença crucial. Os movimentos performativos atuais, ao contrário do que se viu nas bandas desenhadas underground, não são orientados por propósitos utópicos contrários à burguesia. O que mudou nos dias atuais não é apenas a quantidade ou a difusão, mas o potencial subversivo. Ainda que reprove algumas dessas condutas exibicionistas e performativas, a sociedade atual parece não se escandalizar mais com esse tipo de imagem, pois, em algum nível ou grau, muitos o fazem, ainda que seja mostrar para o mundo seu lanche vespertino, imagens de um dia na praia ou compartilhar as brincadeiras dos filhos em casa.

Paula Sibilia (2015) afirma que a autorreferência e os relatos autobiográficos eram mal vistos no passado, e a autopromoção era considerada algo vergonhoso. O exibicionismo atual é fruto do momento em que vivemos, o de uma cultura midiática desenvolvida, onipresente, com enormes e crescentes viabilidades técnicas e que revela "uma dimensão performativa que hoje se destaca nesse tipo de produções. Com esse ambíguo realismo que também prolifera hoje em dia, convoca-se a vida comum para que ela performe em cena" (Sibilia 2015: 355).

Atualmente, com a proliferação dos meios audiovisuais e digitais de produção e distribuição de imagens, as narrativas/performances de autores/personagens redundam em novos repertórios de subjetividades e visibilidades. Nesse sentido, a modernidade parece estar intimamente ligada à dinâmica atual desses novos registros. Ainda que a televisão e a internet potencializem e aumentem a quantidade de novas imagens e narrativas tanto de pessoas comuns quanto de discursos em primeira pessoa, que se tornam celebridades rapidamente e são vistas quase que imediatamente em diversas 
partes do mundo, os exemplos aqui propostos, e em especial nas BDs, reforçam a ideia de que essa parece ser uma condição inerente às próprias mídias.

Coincidentemente, a modernidade na literatura, nas bandas desenhadas, no cinema e na televisão começou quando afloraram as narrativas das pessoas comuns que se tornaram personagens das mídias e posteriormente até mesmo personagens autobiográficos - e que hoje se desdobraram para a exposição de suas intimidades como performance. Assim, pode-se dizer que o homem comum, tomando parte dos diferentes meios, com suas narrativas, evidencia a maturidade das mídias e sua entrada na modernidade, seja pelas bandas desenhadas documentais de Will Eisner, Adrian Tomine e Daniel Clowes; pelos dramas de De Sica em Ladrões de bicicleta e Rossellini em Roma, cidade aberta; por documentários que dão protagonismo a pessoas normalmente invisíveis como fez Mario Handler em Carlos, cineretrato de un caminante, ou ainda pelos entrevistados do cineasta Glauber Rocha no Programa Abertura na extinta TV Tupi no Brasil. Mais do que um fenômeno da contemporaneidade audiovisual e digital, o homem comum parece uma etapa quase obrigatória do desenvolvimento das mídias.

Talvez ainda caiba aqui uma análise final, a partir desse mapeamento feito na banda desenhada. Graeme Turner, em seu livro Ordinary people and the media (2010), debruça-se sobre a participação de populares nas mídias na contemporaneidade, que se tornam celebridades, e cunha o conceito de virada demótica em oposição às visões mais otimistas, que enxergam nessa participação popular nos conteúdos midiáticos uma efetiva democratização desses espaços. Turner se opõe à teoria de John Hartley, que conceitualiza o "democratainment", conciliando entretenimento e democracia em um neologismo e considerando o fato de que a maior visibilidade dada ao homem comum pelas mídias contemporâneas significa sua democratização. Acertadamente, Turner relativiza o conceito de democracia ao lembrar que os conteúdos e as mídias são operados por empresas, corporações midiáticas que, ao visar ao lucro, se preocupariam menos com a democracia e mais com o entretenimento. Ao observar essa distinção, o autor analisa como a mídia participa da produção de cultura, mas sem esquecer o que representa, para ela, seus interesses comerciais. Nesse sentido, cabe a análise de Márcio Serelle:

A mídia é, para Turner (2010), uma força motivadora primária, cujo imperativo é comercial, ou seja, fundamenta-se, principalmente, em audiência e na geração de uma lógica de participação que deve resultar, sempre, em formatos bem-sucedidos do entretenimento. Assim, segundo ele, esse centro de poder de nossa sociedade não simplesmente medeia identidades, desejos e expectativas acerca do real, mas opera, também, como 'autor' delas. (Serelle, 2014:12) 
Desse modo, ao se revisitar a trajetória dos comix neste artigo, bem como a origem, produção e distribuição dos fanzines a partir da década de 1960, constata-se que, apesar de cinema e televisão situarem-se prioritariamente sobre estruturas comerciais de produção, distribuição e exibição, as bandas desenhadas, por sua vez, podem fornecer novos caminhos de análise.

Produzir BDs é uma atividade trabalhosa, por vezes solitária, e não necessariamente cara. Hoje, inúmeros novos artistas utilizam-se de expedientes tributários dos fanzines e das experiências das décadas de 1960, com impressões de baixo orçamento e distribuição caseira, em que se prioriza, tal qual naquela época, consumar a divulgação em detrimento de efetivamente auferir lucros. Ainda há a alternativa advinda atualmente da internet, de revistas inteiramente digitais, divulgadas por meio de redes sociais e publicadas por ferramentas de blogue gratuitas.

Por outro lado, autores de BDs documentais contemporâneas, como Joe Sacco, Emanuel Guibert, Marjane Satrapi ou mesmo Art Spiegelman, que poderiam direcionar suas narrativas diretamente para reportagens em jornais, livros ou filmes, escolheram a mídia banda desenhada como seu veículo primeiro e principal. Optar por essa mídia significa, em última instância, abrir mão das características dos outros meios, mais comerciais e com mais capilaridade. A BD, dado seu público específico e considerado ainda menor com relação às outras mídias, esfria a reportagem quente do jornal e aquebranta o potencial de marketing do cinema e dos livros, subtraindo sua capacidade de lucros mais vigorosos comparados a estes.

Nesse sentido, poder-se-ia dizer que a banda desenhada é um espaço midiático específico, que, ao contrário de outras mídias, favorece o "democratainment" em vez do "demótico"? É certo que, se hoje a afirmação de Turner é pertinente, por outro lado a constituição teórica de John Hartley encontra eco nos fanzines e comix dos anos 1960 e 1970, quando a BD da contracultura não apenas não se associava aos grandes grupos de mídia como conseguia contundente expressão com produção artesanal e distribuição caseira. Talvez, partindo dessa premissa, o demótico seja o habitual, mas o democrático, ou o "democratainment", seja ainda possível, e as bandas desenhadas, especialmente as documentais e seus diferentes subgêneros, em que se evidencia o protagonismo do homem comum e, eventualmente, relatos autobiográficos, estejam hoje entre suas formas de maior expressão.

Para Graeme Turner, "as mídias não funcionam apenas como mediadoras de identidades culturais, mas agora servem à função de tradutoras ou autoras de identidades culturais" (Turner, 2010: 7). Nesse sentido, talvez as bandas desenhadas demonstrem toda a sua potencialidade não apenas em suas histórias, mas em suas afiliações atuais e prestes por vir. 


\section{Conclusão}

Buscou-se neste trabalho relacionar a banalidade das narrativas do homem comum, os discursos autobiográficos e a performance na mídia com a BD documental, a partir das experiências da BD underground e dos fanzines estadunidenses nas décadas de 1960 e 1970, e especialmente dos trabalhos de Robert Crumb e Harvey Pekar. Estes influenciaram decisivamente outros autores da banda desenhada, que, a partir da década de 1990, transformaram essas narrativas em establishment. A banda desenhada desvela sua entrada na modernidade por meio do homem comum enquanto personagem e, de modo complementar, através de narrativas autobiográficas, em que as figuras do autor/narrador/personagem se fundem em uma só pessoa para o leitor. Tais experiências revelam que a banda desenhada, especialmente deste gênero aqui trabalhado, oferece elementos de análise tanto para a constituição da performance quanto para a admissibilidade de um "democratainment", conforme propôs John Hartley, em que pese as críticas de Graeme Turner a este modelo. Mesmo com as novas tecnologias e suportes digitais, através das quais BDs são consumidas também em telas, a possibilidade de uma estrutura de produção e distribuição artesanais não deixa de existir, à semelhança do que acontece com outras artes e domínios, como é o caso cinema de bordas.

Do mesmo modo, discursos autorreferenciais e em primeira pessoa, que exploram o homem comum, acordam-se com a possibilidade de identificação de um atributo nas mídias, o que sugere a sua passagem para modernidade, uma transição que, aparentemente, todas as mídias fizeram em um momento de maior maturidade, inclusive a banda desenhada. O afloramento da performance bem como sua banalização observada na contemporaneidade, ao fim, poderia ser um reflexo natural dessa transição que acontece em todas as mídias. Não seria, de fato, nenhuma novidade trazida por produções midiáticas digitais mas teria sido, sem dúvida, popularizada por estas através de uma gigantesca proliferação desses discursos em função, em parte, de uma maior acessibilidade dos meios de comunicação.

A banda desenhada documental, sempre como ponto de convergência neste artigo, é tributária das experiências de BDs da contracultura, dos fanzines, do comix, de autores como Robert Crumb, Harvey Pekar, Gilbert Shelton, entre outros. Ela agrega características dos personagens comuns, dos relatos autobiográficos, do new jornalism, das investigações históricas e do cinema documentário, a ponto de podermos chamá-la de um quadrinho-verdade, não por de fato exprimir o real, o que é impossível, mas por reproduzir estratégias documentais em seus diferentes subgêneros, influenciados pelas diferentes experiências midiáticas ao longo da história, e por conectar autor, técnicas do 
cinema, do jornalismo e da linguagem de quadrinhos, o que a distingue dos outros gêneros tradicionais.

Há um crescimento inquestionável da BD documental seja em número de leitores e de publicações, nos últimos dez anos: algumas livrarias já destinam espaço cativo para este tipo de literatura em suas prateleiras. Tal crescimento supõe o aumento de interesse tributário das complexidades e possibilidades mostradas aqui e que esses discursos hoje acarretam. Nesse sentido poderia se afirmar que a BD documental talvez seja o gênero que mais revela e traduz a modernidade dentre todas as bandas desenhadas, reunindo o banal, a vida cotidiana, a reflexividade, os discursos em primeira pessoa, a metalinguagem e a performance. É, portanto, um objeto de análise que se revela distinto em sua constituição e originalidade, em seu próprio meio, e que deve adquirir maior relevância nos estudos de comunicação.

\section{Bibliografia}

Baudelaire, C. (1996). Sobre a Modernidade. São Paulo: Paz e Terra.

Cirne, M. (2000). Quadrinhos, sedução e paixão. Petrópolis: Vozes.

Davidson, S. (1970). Gung Ho! All American comicks. Amsterdão: OM \& Arcanum. Eco, U. (2001). Apocalípticos e integrados. São Paulo: Perspectiva.

Figueiredo, V. L. (2014). Fábulas da vida obscura: imagens técnicas e anonimato. Revista Rumores. No 15, V. 8, 7-26.

Fresnault-Deruelle, P. (1980). O espaço interpessoal nos comics. In Helbo, André (ed.). Semiologia da representação (pp.125-135). São Paulo: Cultrix.

Moya, A. (1986). História das histórias em quadrinhos. Porto Alegre: L\&PM.

Muanis, F. (2013). O quadrinho documental e a tradução da cidade. Revista Nona Arte, V. 2, No 1, 45-67.

Muanis, F. (2014). Dokumentarische Comics als Übersetzung des Alltäglichen. Zeitschrift für Medienwissenschaft. No 11, 49-64.

Pekar, H. (2006). Bob \& Hary: dois anti-heróis americanos. São Paulo: Conrad. Sahagun, A. (1971). El comic de la contracultura. Estudios de Información: los comics, $N^{\circ} 19-20,239-276$.

Schikowski, K. (2009). "Folks, I'm going to speak plain...": Robert Crumb und die Entwicklung der autobiographischen Comic-Erzählung. Text + Kritik: comics, mangas, graphic novels. V. 9., 90-109.

Serelle, M. (2014). A guinada dos populares: mídia e vida social no Brasil. In Anais do XXIII Encontro Anual da COMPÓS. Belém do Pará: UFPA. 
Sibilia, P. (2015). Autenticidade e performance: A construção de si como personagem visível. Revista Fronteiras: Estudos Midiáticos, V. 17, Nº.3, 353-354. Consultado em: http://revistas.unisinos.br/index.php/fronteiras/article/view/fem.2015.173.09/4984 Sibilia. P. (2008). O show do eu: a intimidade como espetáculo. Rio de Janeiro: Nova Fronteira.

Turner, G. (2010). Ordinary people and the media: the demotic turn. Londres: Sage.

Vigil, L. (1971). El comic underground em los estados unidos. Estudios de Información: los comics, No. 19-20, 101-128.

Felipe Muanis é doutorado em Comunicação Social pela Universidade Federal de Minas Gerais (UFMG). É ilustrador, jornalista, professor do Departamento de Cinema e Vídeo e do Programa de Pós-Graduação em Comunicação da Universidade Federal Fluminense (UFF). Coordena o ENTELAS, grupo de pesquisa em televisão, imagem, teoria e recepção. Atualmente é ainda professor visitante do DAAD (Deutscher Akademischer Austauschdienst) no Institut für Medienwissenschaft na Ruhr-Universität Bochum, Alemanha, e no IMACS - International Master of Audiovisual and Cinema Studies. É autor do livro Audiovisual e Mundialização: televisão e cinema. 